\title{
Cinética de Degradação de Alguns Volumosos Usados na Alimentação de Cabras Leiteiras por Intermédio da Técnica de Produção de Gases sob Diferentes Níveis de pH ${ }^{\mathbf{1}}$
}

\author{
André Luigi Gonçalves ${ }^{2}$, Rogério de Paula Lana ${ }^{3}$, Marcelo Teixeira Rodrigues ${ }^{3}$, Ricardo \\ Augusto Mendonça Vieira ${ }^{4}$, Augusto César Queiroz ${ }^{3}$, Douglas Sampaio Henrique ${ }^{5}$
}

\begin{abstract}
RESUMO - Os objetivos do presente estudo foram a caracterização e a determinação das estimativas dos parâmetros relativos à cinética de degradação ruminal dos carboidratos contidos nas amostras dos volumosos feno de alfafa, capim-elefante, feno de Tifton 85 e silagem de milho em cabras submetidas a diferentes relações volumoso:concentrado. Os parâmetros cinéticos da degradação ruminal da matéria seca e da fibra em detergente neutro destes volumosos, submetidos a diferentes níveis de $\mathrm{pH}$, foram estimados por meio de incubações anaeróbicas, usando as técnicas da produção cumulativa de gases e de subtração de curvas e contrastado com os resultados obtidos por intermédio das técnicas in sito e in vitro, para os parâmetros de degradabilidade específica (DE) e taxa de digestão da fração insolúvel potencialmente digerível (c). A interpretação cinética foi feita pelo modelo logístico $\mathrm{V}(\mathrm{t})=\mathrm{V}_{\mathrm{f}} /(1+\exp (2+4 \mathrm{c}(\mathrm{L}-\mathrm{T})))$. No ensaio de digestibilidade, utilizou-se o tampão de McDougall, adaptado porGonzáles, ajustado com solução de ácido cítrico $1 \mathrm{M}$, para os pHs observados nos animais, conforme a relação volumoso:concentrado (100:0, 80:20, 60:40, 40:60 e 20:80). Observouse comportamento similar nas curvas da degradabilidade específica, bem como para a taxa de digestão da fração insolúvel potencialmente digerível, o que confirma a interferência do nível do $\mathrm{pH}$ sobre os parâmetros relativos à cinética de degradação ruminal dos carboidratos. As leituras de produção de gás resultaram em menores coeficientes de variação para a cinética de degradação da MS, mas apresentaram valores inferiores aos obtidos pelas técnicas in situ e in vitro. Já para a FDN, mostraram valores e comportamento bem próximos dos obtidos pelas outras técnicas. Conclui-se que as estimativas das taxas de degradação ruminal da FDN podem ser realizadas precisamente pela técnica da produção de gás.
\end{abstract}

Palavras-chave: técnica metabólica, degradação da fibra

\section{Degradation Kinetics of Forages Fed to Dairy Goats by Using the Gas Production Approach under Different pH levels}

\begin{abstract}
The objectives of the present study were to characterize and estimate parameters of kinetics of carbohydrate degradation using alfalfa hay, elephant grass, tifton 85 , and corn silage, fed to dairy goats under different forage: concentrate ratio. Kinetic parameters of dry matter and neutral detergent fiber degradation at different $\mathrm{pH}$ values were estimated by using cumulative gas production technique and their values contrasted with those obtained by both in vitro and in situ studies. Kinetic interpretation for specific degradability, rate of degradation and the potentially digestible insoluble fraction was done by using the logistic model $\mathrm{V}(\mathrm{t})=\mathrm{V}_{\mathrm{f}} /(1+\exp (2+4 \mathrm{c}(\mathrm{L}-\mathrm{T})))$. A modified McDougall buffer was used for the in vitro assay to adjust $\mathrm{pH}$ to the values observed in the animals, by adding $1 \mathrm{M}$ of citric acid solution according to the roughage to concentrate ratio studied of 100:0, 80:20, 60:40, 40:60 e 20:80. Similar pattern was found for extent and rate of degradation of the potentially digestible insoluble fraction which confirm the interference of $\mathrm{pH}$ on kinetic parameter of carbohydrates in the rumen. Gas production approach yielded the lowest variation coefficient for the values of dry matter degradation but lower figures were found as compared to both in situ and in vitro techniques. Similar values were found for NDF as the three approaches were compared and it was suggested that they can be used interchangeably to precisely estimate NDF degradation.
\end{abstract}

Key Words: metabolic technique, fiber degradation

\section{Introdução}

Os carboidratos são a principal reserva da energia contida nas plantas, constituindo 50 a $80 \%$ da matéria seca das forrageiras e dos cereais (VAN SOEST, 1994). Para os ruminantes, representam a principal fonte de energia para manutenção de suas funções fisiológicas, devido à fermentação microbiana, convertendo-os em ácidos graxos voláteis (AGVs).

O sistema The Cornell Net Carbohydrate and Protein System (CNCPS) classifica os carboidratos totais, em conformidade com suas taxas de digestão, em fração A (açúcares solúveis), que é prontamente fermentada no rúmen; fração $\mathrm{B}_{1}$ (amido e pectina), que apresenta taxa intermediária de digestão; fração $\mathrm{B}_{2}$ (celulose e hemicelulose), correspondendo à fra-

\footnotetext{
1 Parte da tese de Mestrado apresentada à UFV para obtenção do título "Magister Scientiae".

${ }^{2}$ Mestre em Zootecnia/UFV. E.mail: luigi@mail.ufv.br

${ }^{3}$ Professor da UFV.

${ }^{4}$ Professor da UEG; Pesquisador do Instituto Melon, Silvânia, GO

${ }^{5}$ Estudante de graduação/UFV.
} 
ção lenta e potencialmente digerível da parede celular; e fração C, representada pela porção indigerível ao longo do TGI (SNIFFEN et al., 1992).

Os açúcares solúveis em água - amido e pectina são rápida e completamente digeríveis no TGI. Contudo, a celulose e hemicelulose, basicamente, são lenta e parcialmente disponíveis, além de ocuparem espaço no trato gastrintestinal (TGI), uma vez que compreendem os polímeros, que compõem a parede celular vegetal, juntamente com a lignina, desempenhando funções de sustentação e proteção. Por este motivo, poderiam ser classificados como carboidratos nãoestruturais (CNE) e estruturais (CE), de acordo com o seu comportamento no TGI (MERTENS, 1987; MERTENS, 1996).

Em relação à sua solubilidade, os alimentos utilizados nas rações para ruminantes podem ser divididos nas frações solúveis em tampões aquosos ou nas soluções de detergente neutro, bem como nas frações insolúveis nestes solventes (SCHOFIELD e PELL, 1995). A fração solúvel em detergente neutro é constituída de amido, pectina, açúcares simples, compostos nitrogenados, lipídios e minerais, enquanto a fração insolúvel em detergente neutro enquadra a celulose, a hemicelulose e a lignina (VAN SOEST, 1994). A importância do conhecimento da quantidade e da dinâmica de degradação ruminal destas frações reside no fato destas proporcionarem diferenças significativas na produção de AGVs e no crescimento microbiano ruminal (SCHOFIELD e PELL, 1995).

A procura por métodos acurados, simples e rápidos, para estimar a qualidade dos alimentos, tem sido objetivo de investigações na nutrição de ruminantes (PELL e SCHOFIELD, 1993). As técnicas de avaliação dos parâmetros cinéticos da degradação ruminal dos alimentos compreendem estudos sobre o desaparecimento da massa de amostra incubada ou a quantificação dos produtos finais da atividade microbiana, durante o período de incubação, com os microrganismos ruminais (PELL et al., 1994).

O conhecimento da digestão ruminal dos carboidratos solúveis é escasso, pois o método in situ, convencionalmente usado para estimar os parâmetros cinéticos da degradação ruminal, mede odesaparecimento gravimétrico da fração insolúvel do alimento (SCHOFIELD e PELL, 1995). Dessa forma, apenas empregando-se produção microbiana de gases, é possível estimar os parâmetros cinéticos da degradação dos carboidratos solúveis.

A técnica in situ permite o contato íntimo do alimento-teste com o ambiente ruminal, não existindo melhor forma de simulação do ambiente ruminal, embora o alimento não esteja sujeito a todos os eventos digestivos (VAN SOEST, 1994). Essa técnica requer a utilização de animais fistulados no rúmen, para que as bolsas sejam incubadas por determinados períodos de tempo. A determinação do valor nutritivo in situ permite obter valores mais próximos dos encontrados nos ensaios in vivo (NOCEK, 1988; MERTENS, 1993). Os maiores problemas encontrados neste método são a ação filtrante do tecido de náilon, que permite a passagem de pequenas partículas em ambos sentidos, e a manutenção de animais canulados; além disso, o método in situ apresenta maior variação, quando comparado ao sistema in vitro (VAN SOEST, 1994).

As vantagens da utilização da técnica in vitro residem na sua rapidez, na uniformidade físico-química do microambiente de fermentação e na conveniência de não se manterem tantos animais fistulados. A maioria dos métodos in vitro, no entanto, pode apresentar falhas, por não se utilizarem adequadamente o inóculo, os tampões, ou os equipamentos que garantam as condições de $\mathrm{pH}$, anaerobiose, biomassa microbiana e nutrientes essenciais para a mesma (VAN SOEST, 1994). A principal desvantagem do método in vitro é não reproduzir o ambiente ruminal.

A taxa de degradação da fração fibrosa, apesar de ser normalmente obtida a partir de técnicas gravimétricas, apresenta limitações, pois são laboriosas, além de apresentarem baixa repetibilidade e não permitirem a determinação das taxas de digestão da fração solúvel dos alimentos, uma vez que as alterações da massa incubada nos tempos iniciais de fermentação são relativamente pequenas, o que dificulta a sua mensuração (SCHOFIELD et al., 1994). Devido às limitações impostas por estas técnicas, o método que mensura a produção cumulativa dos gases tem sido utilizado com sucesso para estimativa das taxas de digestão das frações solúveis e insolúveis dos carboidratos, com base no princípio de que os gases produzidos são oriundos do metabolismo microbiano, a partir da fermentação do material incubado (PELL e SCHOFIELD, 1993; MALAFAIA et al., 1998a). A técnica consiste na incubação do alimento a ser testado, acrescido de líquido de rúmen e meio tamponado, em frascos hermeticamente fechados, nos quais, ao longo do tempo, são realizadas leituras de pressão e, ou, volume dos gases produzidos no processo fermentativo.

THEODOROU et al. (1994) desenvolveram uma metodologia mais sensível para estimar a taxa de degradação ruminal dos nutrientes, destacando-se 
hoje os sistemas computadorizados (PELL e SCHOFIELD, 1993), semi-automatizados (THEODOROU et al., 1994) e manométricos (MALAFAIA et al., 1998). As maiores vantagens da técnica, segundo os autores citados, são a nãodestruição da amostra em cada tempo, o que torna a técnica menos laboriosa, não necessitando de grandes quantidades de amostra, e a detecção da contribuição das frações solúveis dos alimentos, o que é de grande interesse, porque esta fração contribui energeticamente para o rápido crescimento microbiano no rúmen, principalmente nos tempos iniciais de digestão.

PELL et al. (1994) também relataram limitações da técnica de produção de gás, que estão relacionadas à contribuição do $\mathrm{CO}_{2}$ resultante do bicarbonato contido no meio de cultura, à deficiência em nutrientes essenciais ao crescimento microbiano pode resultar em estimativas menos exatas e ao fato de a interpretação dos dados de produção cumulativa de gás exigir modelos matemáticos mais complexos que os utilizados na interpretação dos dados gravimétricos de desaparecimento dos nutrientes.

Considerando que os carboidratos são a principal fonte de energia para o crescimento microbiano e a proteína microbiana, a principal fonte de aminoácidos para o hospedeiro, as variações em suas frações, bem como nas taxas de digestão entre e dentro de alimentos, podem afetar o suprimento de proteína microbiana ao intestino delgado e, conseqüentemente, o desempenho animal. Dessa forma, torna-se de vital importância o estudo da cinética de digestão dos carboidratos, para que se consiga, por meio de dietas adequadas, sincronizar a disponibilidade de energia e $\mathrm{N}$ no rúmen, permitindo o máximo desempenho das populações microbianas (RUSSELL et al., 1992).

Os objetivos do presente estudo foram a caracterização e a determinação das estimativas dos parâmetros relativos à cinética de degradação ruminal dos carboidratos contidos nas amostras dos volumosos feno de alfafa, capim-elefante variedade mineiro, feno de capim Tifton 85 e silagem de milho, em cabras submetidas a dietas com diferentes relações volumoso: concentrado, utilizando as técnicas da produção cumulativa de gases e de subtração de curvas. Objetivou-se, ainda, contrastar estes resultados com aqueles obtidos por intermédio das técnicas in situ e in vitro, para os parâmetros de degradabilidade efetiva (DE) e taxa de digestão da fração insolúvel potencialmente digerível (c).

\section{Material e Métodos}

O presente experimento foi conduzido no Setor de Caprinocultura e no Laboratório de Nutrição Animal do Departamento de Zootecnia da Universidade Federal de Viçosa.

Foram utilizadas cinco cabras adultas da raça Alpina, com peso médio de $58,00 \mathrm{~kg} \pm 2,75$, nãoprenhes, não-lactantes e fistuladas no rúmen. Os animais permaneceram confinados em baias individuais, onde receberam sua alimentação.

Foram utilizadas cinco relações volumoso: concentrado para o estudo da degradabilidade in situ, 100:0, 80:20, 60:40, 40:60 e 20:80, o que proporcionou cinco valores distintos de $\mathrm{pH}$, conforme descrito por GONÇALVES (2001a).

Utilizou-se feno de gramínea (Tifton 85) como volumoso. Os ingredientes do concentrado foram o fubá de milho e o farelo de soja, em quantidade suficiente que permitissem a formulação isoprotéica com $12 \% \mathrm{~PB}$.

As amostras dos alimentos, imediatamente após a sua coleta, com exceção dos fenos, foram pré-secas em estufa de ventilação forçada a $55^{\circ} \mathrm{C}$, durante 72 horas. Posteriormente, todos os alimentos foram moídos em peneira de $1 \mathrm{~mm}$ e analisados para matéria seca (MS), proteína bruta (PB), cinzas (CZ) e extrato etéreo (EE), segundo ASSOCIATION OF OFFICIAL ANALYTICAL CHEMISTS - AOAC (1990), além das análises de fibra insolúvel em detergente neutro (FDN), fibra insolúvel em detergente ácido (FDA) e lignina (VAN SOEST et al., 1991). Na Tabela 1, encontra-se a composição bromatológica das forragens utilizados no experimento.

Os procedimentos adotados para as análises in situ e in vitro são os apresentados por GONÇALVES (2001b).

O preparo das amostras para as incubações in vitro, pela técnica de produção de gás, foi realizado tomando-se, aproximadamente, $5 \mathrm{~g}$ de amostra seca ao ar (ASA), moída em peneira a $1 \mathrm{~mm}$, submetida à fervura durante 1 hora em solução detergente neutra. O resíduo obtido foi filtrado em saco de náilon e lavado exaustivamente com água quente e acetona, para retirar completamente qualquer resíduo do detergente, e levado à estufa de ventilação forçada a $55^{\circ} \mathrm{C}$, durante 48 horas.

Foram depositados separadamente em frascos de vidro de $50 \mathrm{~mL}$, aproximadamente, $100 \mathrm{mg}$ de MS e a devida proporção em FDN. Foi infundido $\mathrm{CO}_{2}$ na solução tampão de McDougal (McDOUGAL, 1949) até que o $\mathrm{pH}$ atingisse, aproximadamente, 7,3; em 
Tabela 1 - Composição bromatológica das forrageiras utilizadas no experimento, como integrante da dieta ou como amostra incubada

Table 1 - Chemical composition of forage used in the experiment, as diet component or incubated sample

\begin{tabular}{|c|c|c|c|c|c|c|c|c|}
\hline $\begin{array}{l}\text { Alimento } \\
\text { Feed }\end{array}$ & $\begin{array}{l}\text { MS } \\
D M \\
\end{array}$ & $\begin{array}{l}\mathrm{PB} \\
C P\end{array}$ & $\begin{array}{l}\text { FDN } \\
N D F\end{array}$ & $\begin{array}{l}\text { FDA } \\
A D F\end{array}$ & CHOs & $\begin{array}{c}\text { Cinzas } \\
\text { Ash } \\
\end{array}$ & $\mathrm{Ca}$ & $\mathrm{P}$ \\
\hline & \multicolumn{8}{|c|}{$\begin{array}{l}\text { Alimento utilizado na dieta } \\
\text { Feed used in the diet }\end{array}$} \\
\hline \multirow{2}{*}{$\begin{array}{l}\text { Feno experimento } \\
\text { Experiment hay }\end{array}$} & 90,01 & 12,02 & 72,30 & 31,08 & 8,02 & 6,23 & 0,51 & 0,32 \\
\hline & \multicolumn{8}{|c|}{$\begin{array}{l}\text { Alimentos utilizados na incubação } \\
\text { Feeds used in the incubation }\end{array}$} \\
\hline $\begin{array}{l}\text { Capim-elefante } \\
\text { Elephant grass }\end{array}$ & 21,01 & 8,62 & 67,12 & 38,05 & 10,40 & 2,45 & 0,60 & 0,28 \\
\hline $\begin{array}{l}\text { Feno alfafa } \\
\text { Alfalfa hay }\end{array}$ & 91,04 & 19,24 & 48,26 & 32,59 & 25,32 & 9,05 & 1,58 & 0,12 \\
\hline $\begin{array}{l}\text { Feno Tifton } 85 \\
\text { Tifton } 85 \text { hay }\end{array}$ & 89,02 & 9,28 & 72,3 & 43,8 & 6,12 & 6,81 & 0,39 & 0,18 \\
\hline $\begin{array}{l}\text { Silagem de milho } \\
\text { Corn silage }\end{array}$ & 31,88 & 7,48 & 52,30 & 25,48 & 28,41 & 1,19 & 0,22 & 0,26 \\
\hline
\end{tabular}

seguida separou-se o tampão para acondicionamento em cinco béqueres de $500 \mathrm{~mL}$ e efetuou-se a adição gradual de solução de ácido cítrico $1 \mathrm{M}$ (GRANT e WEIDNER, 1992), até atingir os valores de $\mathrm{pH}$ observados no rúmen das cabras, de 5,$85 ; 6,20 ; 6,55 ; 6,85$; e 7,05, quando alimentadas com as dietas contendo diferentes proporções de concentrado. Em cada frasco de incubação, foram adicionados $8 \mathrm{ml}$ da solução tampão, sob aspersão de $\mathrm{CO}_{2}$, para que as condições anaeróbicas fossem mantidas. Em seguida, foram inoculados $2 \mathrm{~mL}$ de líquido de rúmen caprino filtrado, em conformidade com as faixas de $\mathrm{pH}$, ou seja: 5,88 ; 6,$19 ; 6,53 ; 6,89 ;$ e 7,03 . O líquido de rúmen foi coletado das cinco cabras, identificado quanto ao tratamento, acondicionado em garrafas térmicas e inoculado nos frascos de mesma faixa de $\mathrm{pH}$, sempre sob saturação de $\mathrm{CO}_{2}$, os quais foram, após inoculação, imediatamente vedados com tampa de borracha, lacrados com dispositivo de alumínio e mantidos em sala climatizada, a $39^{\circ} \mathrm{C}$, em mesa de agitação orbital automática.

As leituras da pressão e volume dos gases foram realizadas por meio de um multímetro com sensor de pressão, conforme descrito por PELL e SCHOFIELD (1993), nos tempos 1/2, 1, 2, 3, 4, 5, 6, 9, 12, 18, 24, 30, 36, 48, 60 e 72 horas após o início da incubação. Para descontar o volume de gás oriundo do líquido de rúmen e do tampão, dois frascos foram incubados sem amostra (branco); dessa forma, para cada tempo de leitura, o volume de gás dos frascos com amostra foi subtraído do volume dos frascos sem amostra. Com o somatório do volume de gás para cada tempo de leitura, foram construídas as curvas de produção cumulativa dos gases oriundos da MS e FDN, sendo a curva correspondente à fração solúvel em detergente neutro (CNE), obtida pela diferença entre o gás da MS e da FDN para cada tempo de incubação. A cinética da produção cumulativa dos gases oriundos das frações de CNE e FDN foi analisada empregando-se o modelo logístico unicompartimental (SCHOFIELD et al., 1994):

$$
\mathrm{V}(\mathrm{t})=\frac{\mathrm{Vf}}{1+\exp [2-4 \times \mathrm{c} \times(\mathrm{t}-\mathrm{L})]}
$$

em que $V(t)$ é o volume acumulado no tempo $t$; $\mathrm{Vf}(\mathrm{mL} / 100 \mathrm{mg} \mathrm{MS})$, o total de gás produzido a partir da fração em questão; c $\left(\mathrm{h}^{-1}\right)$, a taxa de degradação da fração potencialmente degradável dos carboidratos contidos na matéria seca ou na parede celular insolúvel em solução detergente neutra; L, a latência discreta (h); e t, o tempo (h). As taxas de degradação ruminal dos CNE e da FDN foram estimadas como c/ $V_{f}$; em que c equivale à taxa máxima de produção de gás. Os parâmetros cinéticos relativos à fração de CNE foram estimados a partir da produção cumulativa de gás até 12 horas de incubação, ou até o momento em que a assíntota fosse estabelecida (STEFANON et al., 1996; DOANE et al., 1997; e DOANE et al., 1998). Para a realização dos ajustes, utilizou-se o processo interativo do algoritmo de Marquadt, implantado no programa Sistema de análises estatísticas e genéticas - SAEG (UNIVERSIDADE FEDERAL DE VIÇOSA - UFV, 2000). 
A conversão dos valores observados por intermédio do voltímetro (mvolt), em volume de gás (mL), foi realizada considerando-se que 1 mvolt corresponde a 7,68 mL de gás (PELL e SCHOFIELD, 1993).

O conteúdo de cada frasco, retirado ao final incubação, foi transferido para um cadinho filtrante ( $\varnothing$ médio dos poros entre 40 e $60 \mathrm{~mm}$ ), de massa previamente conhecida, que, em seguida, foi depositado em béquer de $500 \mathrm{~mL}$, ao qual se adicionaram $100 \mathrm{~mL}$ de solução detergente neutra por grama de amostra. Após uma hora de fervura, filtrou-se o conteúdo do béquer no mesmo cadinho, utilizando-se água destilada quente para a lavagem e transferência do resíduo final, com subseqüente lavagem com acetona $(50 \mathrm{~mL})$. Ao final, o cadinho contendo o resíduo foi levado à estufa $\left(105^{\circ} \mathrm{C}\right)$ para secagem e posterior pesagem.

Os valores de c foram obtidos diretamente a partir do modelo logístico unicompartimental proposto por SCHOFIELD et al. (1994), para a cinética da produção cumulativa dos gases oriundos das frações de CNE e FDN. A DE estimada para a MS, com base na cinética da produção de gases, foi calculada a partir do resultado da DEA mais a DEFDN. A DEA foi obtida a partir do produto de A (fração solúvel em detergente neutro) por sua taxa de digestão dividido pelo resultado de sua taxa de digestão mais a taxa de passagem, e a DEFDN, a partir da FDN potencialmente digerível (FDNpd $=100$ (A-I)) multiplicada por sua taxa de digestão estimada pelo gás, dividido pelo resultado da sua taxa de digestão mais a taxa de passagem. A taxa de passagem considerada $(0,032)$ foi a observada por SILANIKOVE et al. (1993) para animais da raça Saanen, em condições semelhantes às do presente estudo.

\section{Resultados e Discussão}

A primeira pressuposição feita para utilização da técnica de produção de gás é que este, gerado nos frascos de fermentação, utilizado para interpretação das características nutricionais para estimar a taxa de digestão das frações que compõem o alimento, é oriundo exclusivamente da fermentação do material incubado (CABRAL, 1999). Contudo, PELL et al. (1994) relataram limitações da técnica de produção de gás, que estão relacionadas à contribuição do $\mathrm{CO}_{2}$, resultante do bicarbonato contido no meio de cultura. Entretanto, a Figura 1 ilustra a relação entre o desaparecimento de FDN incubada e a produção de gás, em que se observa relação linear $\left(\mathrm{r}^{2}=0,9977\right)$, como sugerido por PELL e
SCHOFIELD (1993), o que fornece subsídios para garantir que a técnica pode ser utilizada para a estimativa do valor nutricional de alimentos.

Embora existam diferenças numéricas entre os parâmetros cinéticos estimados pelas técnicas in situ e in vitro e os observados pela técnica de produção de gás (Tabela 2), possível explicação para a similaridade entre as curvas é que a combinação entre todos os parâmetros do modelo resulta em pontos estimados semelhantes. Outra explicação para esta similaridade é que o meio nutritivo-tamponante utilizado foi eficaz na manutenção de valores de $\mathrm{pH}$, dentro das faixas desejadas de 5,$85 ; 6,20 ; 6,55 ; 6,85$; e 7,05, para todos os alimentos estudados.

Vale ressaltar que a comparação dos dados referentes às taxas de digestão das frações FDN e CNE, obtidas neste estudo, com as estimativas de MALAFAIA et al. (1998b) ou SCHOFIELD e PELL (1995), é imprópria, uma vez que aqueles autores utilizaram modelos bicompartimentais para estas estimativas, partindo da pressuposição de que cada fração apresentava natureza heterogênea. Entretanto, neste trabalho, considerando as frações de carboidratos sugeridas pelo CNCPS, conforme SNIFFEN et al. (1992), as quais são consideradas isoladamente como uma fração homogênea, foram utilizados modelos unicompartimentais para a obtenção

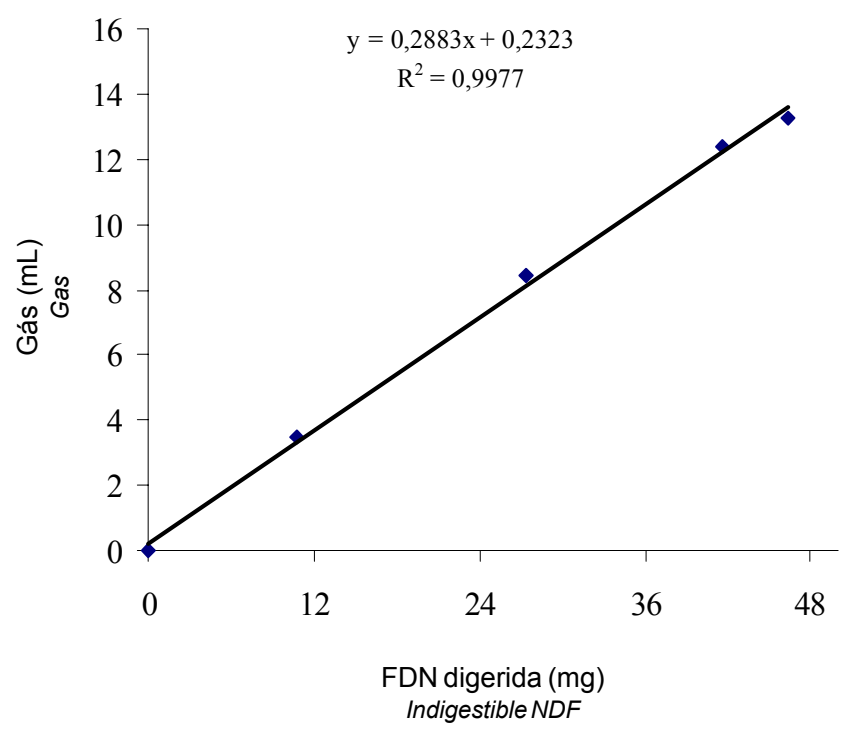

Figura 1 - Modelo para a relação entre a produção de gás e o desaparecimento da massa de FDN incubada.

Figure 1 - Model for the relation between gas production and incubated NDF mass disappearance. 
Tabela 2 - Valores obtidos para volume final de gás (VF) e taxa de degradação da fração potencialmente degradável insolúvel em detergente neutro (c), para os volumosos avaliados nos diferentes níveis de $\mathrm{pH}$

Table 2 - Values obtained for final gas volume (FV) and degradation rate of fraction potentially degradable insoluble in neutral detergent fiber (c), for the roughages evaluated in different $\mathrm{pH}$

\begin{tabular}{|c|c|c|c|c|c|c|}
\hline \multirow{3}{*}{$\begin{array}{l}\text { Alimento } \\
\text { Feed }\end{array}$} & \multicolumn{3}{|c|}{$\mathrm{VF}$} & \multicolumn{3}{|c|}{$\mathrm{C}$} \\
\hline & MS & FDN & CNF & MS & FDN & $\mathrm{CNF}$ \\
\hline & $D M$ & $N D F$ & $N F C$ & $D M$ & $N D F$ & $N F C$ \\
\hline & $\mathrm{pH} 7,04$ & & & & & \\
\hline Alfafa & 28,40 & 13,67 & 2,09 & 0,04 & 0,05 & 0,15 \\
\hline Capim & 25,86 & 14,54 & 1,68 & 0,04 & 0,04 & 0,40 \\
\hline Tifton & 22,97 & 19,58 & 1,04 & 0,04 & 0,05 & 0,3 \\
\hline Silagem & $\begin{array}{r}31,68 \\
\text { pH } 6,85\end{array}$ & 14,61 & 9,57 & 0,05 & 0,04 & 0,12 \\
\hline Alfafa & 39,30 & 26,93 & 8,93 & 0,07 & 0,07 & 0,11 \\
\hline Capim & 30,12 & 29,10 & 6,48 & 0,07 & 0,08 & 0,18 \\
\hline Tifton & 36,63 & 33,56 & 2,68 & 0,07 & 0,08 & 0,25 \\
\hline \multirow[t]{2}{*}{ Silagem } & $\begin{array}{r}42,29 \\
\end{array}$ & 26,75 & 18,00 & 0,10 & 0,06 & 0,16 \\
\hline & pH 6,55 & & & & & \\
\hline Alfafa & 36,32 & 26,16 & 8,49 & 0,08 & 0,08 & 0,20 \\
\hline Capim & 39,74 & 30,59 & 7,87 & 0,07 & 0,08 & 0,12 \\
\hline Tifton & 36,71 & 30,06 & 5,21 & 0,08 & 0,07 & 0,29 \\
\hline \multirow[t]{2}{*}{ Silagem } & 44,54 & 23,33 & 19,55 & 0,10 & 0,07 & 0,15 \\
\hline & pH 6,21 & & & & & \\
\hline Alfafa & 34,95 & 27,80 & 5,86 & 0,08 & 0,08 & 0,20 \\
\hline Capim & 36,84 & 30,89 & 5,43 & 0,07 & 0,07 & 0,15 \\
\hline Tifton & 36,86 & 38,59 & 4,35 & 0,08 & 0,07 & 0,25 \\
\hline \multirow[t]{2}{*}{ Silagem } & 36,90 & 22,32 & 13,58 & 0,09 & 0,07 & 0,15 \\
\hline & pH 5,83 & & & & & \\
\hline Alfafa & 33,61 & 29,03 & 3,28 & 0,08 & 0,08 & 0,18 \\
\hline Capim & 33,96 & 31,21 & 2,05 & 0,07 & 0,07 & 0,06 \\
\hline Tifton & 36,10 & 40,00 & 3,45 & 0,09 & 0,07 & 0,16 \\
\hline Silagem & 29,44 & 21,31 & 7,62 & 0,08 & 0,07 & 0,17 \\
\hline
\end{tabular}

das estimativas das taxas de digestão de cada fração.

Estudos in vitro, em valores de $\mathrm{pH}$ inferiores a 6,20 , permitiram demonstrar seu efeito negativo sobre o crescimento dos microrganismos ruminais, especialmente os fibrolíticos (MERTENS e LOFTEN, 1987; PELL et al., 1994), em conformidade com o que pode ser observado em relação aos resultados obtidos neste trabalho, na Figura 2 e Tabela 3.

As incubações in situ e in vitro resultaram em comportamentos das curvas de degradação da matéria seca semelhantes para todos os volumosos (Figura 2).

Os coeficientes de variação encontrados para as leituras de produção de gás foram inicialmente maiores e diminuíram, à medida que aumentou o tempo de incubação. Este comportamento foi função da menor produção de gás durante o período inicial da incubação. A análise destes valores de $\mathrm{CV}$ sugere que a precisão das estimativas das taxas de degradação foi maior para a técnica metabólica, enquanto o método in situ foi o que apresentou maior variação e menor precisão, à semelhança do observado por MADSEN e HVELPLUND (1994) e MALAFAIA (1998b).

As curvas de degradação construídas com a obtenção da fração insolúvel potencialmente digestível (B) e do resíduo indigerível (I), após 72 horas de incubação in vitro, na técnica de produção de gás, elaboradas com as taxas de degradação (c), foram numericamente próximas às estimadas convencionalmente pelos métodos in situ e in vitro, para todos os volumosos estudados (Figura 2).

Os sistemas de exigências nutricionais que incorporam modelos mecanicistas requerem estimativas precisas das taxas de degradação para a predição do desempenho microbiano ruminal e, subseqüentemente, dos animais (VAN SOEST, 1994; PELL et al., 1994).

Os ensaios in situ são realmente úteis para determinados propósitos e constituem as melhores ferramentas empregadas nos estudos iniciais sobre a digestão ruminal, especialmente na época anterior aos atuais recursos computacionais.

Segundo MALAFAIA (1998a), com o advento 
Tabela 3 - Degradabilidade efetiva (DE) da matéria seca (MS) e da fibra em detergente neutro (FDN), por intermédio das técnicas in vitro (IV), in situ (IS) e de produção de gás (G)

Table 3 - Effective disappearance (DE) of dry matter (DM) and neutral detergent fiber (NDF), by the in vitro (IV), in situ (IS) and gas production (GP) techniques

\begin{tabular}{|c|c|c|c|c|c|c|c|c|c|c|c|}
\hline & 7,05 & 6,85 & 6,55 & 6,2 & 5,85 & & 7,05 & 6,85 & 6,55 & 6,2 & 5,85 \\
\hline \multicolumn{8}{|c|}{$\begin{array}{c}\text { Feno de alfafa } \\
\text { Alfalfa hay }\end{array}$} & \multicolumn{4}{|c|}{$\begin{array}{c}\text { Capim-elefante } \\
\text { Elephantgrass }\end{array}$} \\
\hline DEMSIS & 68,13 & 73,47 & 78,64 & 73,46 & 66,74 & DEMSIS & 58,87 & 62,58 & 69,07 & 64,17 & 57,26 \\
\hline DEMSIV & 67,38 & 72,12 & 75,58 & 71,56 & 66,18 & DEMSIV & 59,44 & 65,67 & 72,77 & 65,67 & 61,42 \\
\hline DEMSG & 66,94 & 69,22 & 80,08 & 74,99 & 72,12 & DEMSG & 58,14 & 62,38 & 62,80 & 58,61 & 55,15 \\
\hline DEFDNIS & 23,65 & 28,03 & 30,35 & 24,23 & 20,56 & DEFDNIS & 23,81 & 28,48 & 30,34 & 27,06 & 25,15 \\
\hline DEFDNIV & 24,71 & 25,17 & 28,27 & 26,36 & 24,80 & DEFDNIV & 22,80 & 27,48 & 29,85 & 26,77 & 23,95 \\
\hline DEFDNG & 25,62 & 28,44 & 32,91 & 30,16 & 28,12 & DEFDNG & 27,14 & 32,46 & 34,73 & 30,42 & 27,70 \\
\hline \multicolumn{8}{|c|}{$\begin{array}{l}\text { Feno de Tifton } 85 \\
\text { Tifton } 85 \text { hay }\end{array}$} & \multicolumn{4}{|c|}{$\begin{array}{l}\text { Silagem de milho } \\
\text { Corn silage }\end{array}$} \\
\hline DEMSIS & 45,72 & 50,54 & 54,73 & 48,55 & 42,27 & DEMSIS & 69,87 & 73,85 & 75,32 & 73,55 & 70 \\
\hline DEMSIV & 44,45 & 47,87 & 52,92 & 57,63 & 50,50 & DEMSIV & 63,87 & 68,85 & 78,55 & 76,31 & 64,5 \\
\hline DEMSG & 45,54 & 52,01 & 53,47 & 52,64 & 46,76 & DEMSG & 62,94 & 69,96 & 80,42 & 79,58 & 70,48 \\
\hline DEFDNIS & 24,34 & 28,48 & 31,17 & 30,53 & 26,40 & DEFDNIS & 21,82 & 20,53 & 21,71 & 20,52 & 21,37 \\
\hline DEFDNIV & 20,00 & 26,89 & 29,34 & 27,66 & 23,25 & DEFDNIV & 22,95 & 26,09 & 30,31 & 27,31 & 24, \\
\hline DEFDNG & 30,50 & 35,51 & 35,77 & 31,91 & 30,28 & DEFDNG & 26,21 & 28,47 & 33,38 & 32,72 & 29,24 \\
\hline
\end{tabular}

dos softwares estatísticos, da reparametrização de modelos mecanicistas para explicar eventos ruminais e da crescente pressão para a redução de estudos com métodos invasivos aos animais, os ensaios in situ devem ser empregados apenas para fins específicos, como a comparação entre dietas. Ainda de acordo com esse autor, a caracterização de um alimento pode ser realizada pela obtenção gravimétrica de sua fração solúvel $(a)$ e de seu resíduo indigestível (I), estimados in vitro com meio reduzido-tamponado, e pela estimativa da taxa de degradação, obtida pela técnica de produção microbiana de gás. Dessa maneira, o resíduo insolúvel potencialmente digestível $(B)$ seria calculado como $100-(a+I)$. Em ambos os métodos, o inóculo ruminal poderia ser obtido por meio de sondas oro-nasais ou em abatedouros, o que tornaria desnecessária a manutenção de animais fistulados para tal propósito.

Se o propósito for a estimativa das taxas de degradação de carboidratos, a técnica de produção cumulativa de gás apresenta-se como opção simples, barata e precisa (THEODOROU et al., 1994, PELL et al., 1994). Vale lembrar que a comparação de alimentos deve ser feita sempre por técnicas in vitro, enquanto a comparação entre dietas, bem como os estudos de validação, por técnicas in vivo (MALAFAIA, 1998b).

Ao se compararem os valores para a obtenção dos parâmetros, por intermédio da técnica de produção de gás, foi observado comportamento semelhante ao encontrado para aqueles avaliados pelas técnicas in situ e in vitro. Pode-se inferir que, independentemente do procedimento experimental adotado, obterse-ia o mesmo perfil das variáveis estudadas. Não pode ignorar o fato de que o animal em seu manejo alimentar diário sofre oscilação constante do $\mathrm{pH}$ ruminal, o qual pareceu influenciar o processo de degradação da fibra.

Ao se observar a degradabilidade efetiva da MS obtida nos diferentes níveis de $\mathrm{pH}$, pode-se notar crescimento na faixa de 7\%, ao se alterar o $\mathrm{pH}$ de 7,05 para 6,85 , para os valores de DEIS e DEIV, e de $4 \%$ para DEG para o feno de alfafa. Em contrapartida, quando o $\mathrm{pH}$ mudou de 7,05 para 6,55 , o valor de DEG passou para $19,6 \%$ contra 15,4 e 12,2 para DEIS e DEIV, respectivamente. Até este ponto, a adição de concentrado induz maior TCE, proporcionando maior DE. A partir daí, começa a interferir negativamente no processo digestivo, o que possibilita redução de 9,4\%, para DEIS e DEIV, e 6,4\%, para DEG, quando o pH passa de 6,55 para 6,20. Observou-se maior aumento neste valor, quando o $\mathrm{pH}$ passou de 6,20 para 5,85 . Este comportamento se repete para todos os outros alimentos, de forma bastante semelhante, tanto para a MS quanto para a FDN, como pode ser observado na Tabela 3.

Ao se plotarem os pontos obtidos para a DE da MS e da FDN pelas técnicas IS, IV e de produção de gás, dentro da faixa de $\mathrm{pH}$ observada, para cada alimento (Figura 2), verifica-se, nitidamente, comportamento similar para cada parâmetro, o que 

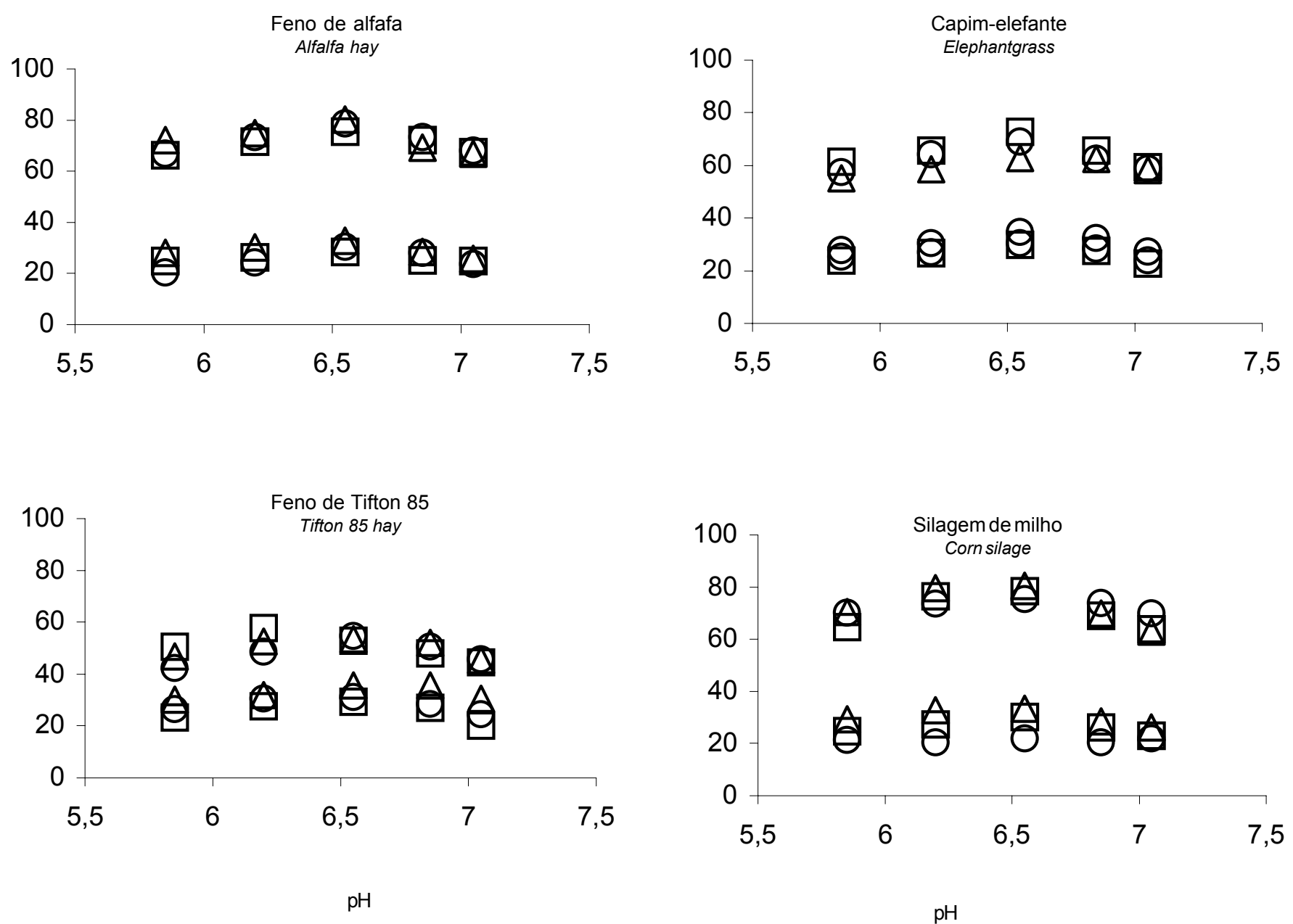

Figura 2 - Curva de DE da MS e da FDN dos volumosos avaliados, nas diferentes faixas de pH, para as técnicas (O) in situ IS, (口) in vitro - IV e (口) produção de gás.

Figure 2 - ED curve of DM and NDF of evaluated roughages, in different pH, by means of in vitro (IV), in situ (IS) and gas production (GP) techniques.

gerou pontos que, quando não estão sobrepostos, se encontram bem próximos.

A taxa c, estimada pela incubação da FDN, por meio da técnica de produção de gás, foi compatível às estimadas in situ ou in vitro em outros estudos (VIEIRA et al., 1997; MALAFAIA et al., 1998b; CABRAL, 1999). Estas taxas podem ser relativas à despolimerização das porções moleculares de difícil ataque microbiano ou daqueles componentes estruturais complexados à lignina.

\section{Conclusões}

Os parâmetros de degradação obtidos pela técnica de produção de gás foram comparáveis aos obtidos com as técnicas tradicionais in situ e in vitro.

A utilização da técnica de produção de gás consistiu em um método mais simples e menos laborioso, apresentando a menor variação entre mensurações para a estimativa das taxas de degradação dos alimentos usados na alimentação de cabras leiteiras. 


\section{Referências Bibliográficas}

ASSOCIATION OF OFFICIAL ANALYTICAL CHEMISTS AOAC. 1990. Official methods of analysis. 15.ed., Arlington, Virginia. $1117 \mathrm{p}$.

CABRAL, L.S. Cinética ruminal das frações de carboidratos e proteinas e digestão intestinal da proteína de alimentos por intermédio de técnicas in vitro. Viçosa: UFV, 1999. 98p. Dissertação (Mestrado em Zootecnia) - Universidade Federal de Viçosa, 1999.

DOANE, P.H., PELL, A.N., SCHOFIELD, P. 1997. The effect of preservation method on the neutral detergent soluble fractions of forages. J. Anim. Sci., 75(4):1140-1148.

DOANE, P.H., PELL, A.N., SCHOFIELD, P. 1998. Ensiling effects on the ethanol fractionation of forages using gas production. J. Anim. Sci., 76(3):888-895.

GRANT, R.J., WEIDNER, S.J. 1992. Digestion kinetics of fiber: influence of in vitro buffer $\mathrm{pH}$ varied within observed physiological range. J. Dairy Sci., 75:1060-1068.

GONÇALVES, A.L., LANA, R.P., RODRIGUES, M.T. et al. 2001a. Padrão nictemeral do $\mathrm{pH}$ ruminal e comportamento alimentar de cabras leiteiras alimentadas com dietas contendo diferentes relações volumoso:concentrado. Rev. bras. zootec., 30(6):1886-1892.

GONÇALVES, A.L., LANA, R.P., RODRIGUES, M.T. et al. 2001b. Degrabilidade ruminal da matéria seca e da fibra em detergente neutro de alguns volumosos utilizados na alimentação de cabras leiteiras, submetidas a dietas com diferentes relações volumoso:concentrado. Rev. bras. zootec., 30(6):1893-1903.

MADSEN, J., HVELPLUND, T. 1994. Prediction of in situ degradability in the rumen. Results of a European ring test. Livest. Prod. Sci., 39:201-214.

MALAFAIA, P.A.M., VALADARES FILHO, S.C., VIEIRA, R.A.M. et al. 1998a. Cinética ruminal de alguns alimentos investigada por técnicas gravimétricas e metabólicas. R. Bras. Zootec., 27(2):370-380.

MALAFAIA, P.A.M., VALADARES FILHO, S.C., VIEIRA, R.A.M. et al. 1998b. Determinação da frações que constituem os carboidratos totais e da cinética ruminal da fibra em detergente neutro de alguns alimentos para ruminantes. R. Bras. Zootec., 27(4):790-796.

McDOUGAL, E.I. 1949. Studies on ruminal saliva. 1. The composition and output of sheep's saliva. Biochem. J., 43(1):99-109.

MERTENS, D.R., LOFTEN, J.R. 1987. The effect of starch on forage fiber digestion in vitro. J. Dairy Sci., 63(9):1437

MERTENS, D.R. 1987. Predicting intake and digestibility using mathematical models of ruminal function. J. Anim. Sci., 64(5):1548-1558.

MERTENS, D.R. 1993. Rate and extent of digestion. In: FORBES, J.M., FRANCE, J. (Eds.) Quantitative aspects of ruminant digestion and metabolism. Cambridge, England: Commonwealth Agricultural Bureaux, Cambridge University Press. p.13-51.

MERTENS, D.R. Using fiber and carbohydrate analyses to formulate dairy rations. In: INFORMATIONAL CONFERENCE WITH DAIRY AND FORAGES INDUSTRIES, 1996, USA, Proceedings... 1996. p.81-92.
NOCEK, J.E. 1988. In situ and other methods to estimate ruminal protein and energy digestibility: a review. J. Dairy Sci., 71(8):2051-2069.

PELL, A.N., SCHOFIELD, P. 1993. Computerized monitoring of gas production to measure forage digestion in vitro. J. Dairy Sci., 76(9):1063-1073.

PELL, A.N., SCHOFIELD, P., STONE, W.C. 1994. Rates of digestion of feeds measured in vitro with computers. Proc. Cornell Nutr. Conf., p.74-81.

RUSSELL, B.J., O'CONNOR, J.D., FOX, D.J. et al. 1992. A net carbohydrate and protein system for evaluation cattle diets: ruminal fermentation. J. Anim. Sci., 70(12):3551-3581.

SCHOFIELD, P., PITT, R.E., PELL, A.N. 1994. Kinetics of fiber digestion from in vitro gas production. J. Anim Sci., 72(11):2980-2991.

SCHOFIELD, P., PELL, A.N. 1995. Validity of using accumulated gas production readings to measure forage digestion in vitro. J. Dairy Sci., 78(11):2230-2238.

SIlANIKOVE, N., TAGARI, H., SHKOLNIK, A. 1993. Comparison of rate of passage, fermentation rate and efficiency of digestion of high fiber diet in desert Bedouin goats compared to Swiss Saanen goats. Small Rum. Res., 12(1):45-60.

SNIFFEN, C.J., O'CONNOR, D.J., VAN SOEST, P.J. et al. 1992. A net carbohydrate and protein system for evaluating cattle diets: carbohydrate and protein availability. J. Anim. Sci., 70(12):3562-3577.

STEFANON, B., PELL, A.N., SCHOFIELD, P. 1996. Effect of maturity on digestion kinetics of water-soluble and waterinsoluble fractions of alfalfa and brome hay. J. Anim. Sci., 74(5):1104-1115.

THEODOROU, M.K., WILLIAMS, B.A., DHANOA, M.S. et al. 1994. A simple gas production method using a pressure transducer to determine the fermentation kinetics of ruminant feed. Anim. Feed Sci. Techn., 48(1):185-197.

UNIVERSIDADE FEDERAL DE VIÇOSA - UFV. 2000. SAEG - Sistema de análises estatísticas e genéticas. Versão 8.0. Viçosa, MG. 142p. (Manual do usuário).

VAN SOEST, P.J. 1994. Nutritional ecology of the ruminant. Ithaca: Cornell University Press. 476p.

VAN SOEST, P.J., ROBERTSON, J.B., LEWIS, B.A. 1991. Methods for dietary fiber, neutral detergent fiber, and nonstarch polysaccharides in relation to animal nutrition. J. Dairy Sci., 74(10):3583-3597.

VIEIRA, R.A.M., PEREIRA, J.C., MALAFAIA, P.A.M. et al. 1997. The influence of elephant-grass (Pennisetum purpureum Schum., Mineiro variety) growth on the nutrient kinetics in the rumen. Anim. Feed Sci. Technol., 67(2-3):151-161.

Recebido em: 21/01/01 Aceito em: 29/07/01 